\title{
Correction to: Increasing newly diagnosed inflammatory bowel disease and improving prognosis in China: a 30-year retrospective study from a single centre
}

Hong Lv ${ }^{\dagger}$, Meng $\mathrm{Jin}^{\dagger}$, Huimin Zhang, Xuanfu Chen, Meixu Wu, Mingyue Guo, Runing Zhou, Zheng Wang, Hong Yang ${ }^{*}$ and Jiaming Qian

\section{Correction to: BMC Gastroenterol (2020) 20:377}

https://doi.org/10.1186/s12876-020-01527-1

After publication of this article [1], the authors reported that in the Results section, in the sentence "The in-hospital mortality for patients with CD decreased from $12.5 \%$ in $1986-1990$ to $1.8 \%$ in $2011-2015$ ", the mortality in 2011-2015 was actually $0 \%$ rather than $1.8 \%$.

The original article [1] has been updated.

\section{Reference}

1. Lv H, Jin M, Zhang $H$, et al. Increasing newly diagnosed inflammatory bowel disease and improving prognosis in China: a 30-year retrospective study from a single centre. BMC Gastroenterol. 2020;20:377. https://doi. org/10.1186/s12876-020-01527-1.

\section{Publisher's Note}

Springer Nature remains neutral with regard to jurisdictional claims in published maps and institutional affiliations. 